\title{
MODERATE TO SEVERE PULMONARY HYPERTENSION ACCOMPANYING PATENT DUCTUS ARTERIOSUS
}

\author{
BY
}

\author{
J. M. REID, J. G. STEVENSON, E. N. COLEMAN, R. S. BARCLAY, T. M. WELSH, \\ W. M. FYFE, AND J. A. INALL \\ From the Cardio-thoracic Unit, Mearnskirk Hospital, The Department of Cardiology, Royal Hospital for Sick Children, \\ Glasgow, and the Department of Child Health, University of Glasgow
}

Received February 3, 1964

Gross and Hubbard (1939) were the first to report the successful surgical treatment of a patient with patent ductus arteriosus. Since then there have been several reports of large series so treated (Gross, 1952; Ellis et al., 1956; Krovetz and Warden, 1962). While there is unanimity that closure of an uncomplicated ductus should be performed, preferably in early childhood, there is considerable controversy as to the wisdom of this procedure in patients with either additional cardiac defects or concomitant pulmonary hypertension. Despite the fact that the pulmonary blood flow may be augmented to two to three times the systemic level, pulmonary hypertension is relatively uncommon in patent ductus arteriosus. Kjellberg et al. (1959) found pulmonary hypertension in 19 out of 138 cases $(14 \%)$, and Wood (1956) quoted a figure of 13 per cent out of 115 cases with the condition. The presence of severe pulmonary hypertension poses the perennial problem of whether to close the ductus.

Our experience with 15 such patients treated surgically is presented; the difficulties that may be encountered are discussed.

\section{PRESENT SeRIES}

Clinical Features. In the past 12 years, 290 patients with patent ductus arteriosus as the sole lesion have been operated on successfully. in this unit. Of these, $15(5 \%)$ had moderate to severe pulmonary hypertension, the main pulmonary artery pressure in all measuring $50 \mathrm{~mm}$. $\mathrm{Hg}$ systolic or above. In the great majority of patients with an uncomplicated patent ductus arteriosus the characteristic physical signs were unmistakable. In those with severe pulmonary hypertension the clinical picture was often equivocal and could on occasion be easily mistaken for that of a ventricular septal defect with pulmonary hypertension. Indeed, 5 of the 15 patients under discussion had been accorded this diagnosis before the correct site of shunt was established at cardiac catheterization.

The Table summarizes the salient features of the 15 patients with moderate to severe pulmonary hypertension. Dyspnœa on exertion was present in 4; a typical continuous murmur was heard in 8 , but in the remainder only a harsh systolic murmur, maximal at the pulmonary area. The second pulmonary sound was greatly accentuated in all, and right ventricular pulsation was noted in 2 . None of the patients was cyanosed, yet in 2, dye indicator curves (Coomassie Blue) suggested bidirectional shunts; albeit the right-to-left shunt appeared minimal. Two patients had electrocardiographic evidence of biventricular hypertrophy, but the pattern of isolated left ventricular hypertrophy was noted in the remainder.

In all 15 patients cardiac catheterization was carried out before operation, principally to establish the diagnosis but also to assess the degree of pulmonary hypertension, and to determine whether 
TABLE

Fifteen Cases of Patent Ductus Arteriosus with Moderate to Severe Pulmonary Hypertension and no OTHER DEFECT

\begin{tabular}{|c|c|c|c|c|c|c|c|c|c|c|c|c|c|}
\hline \multirow[t]{2}{*}{$\begin{array}{l}\text { Case } \\
\text { No. }\end{array}$} & \multirow[t]{2}{*}{ Sex } & \multirow[t]{2}{*}{$\begin{array}{l}\text { Age } \\
\text { (yr.) }\end{array}$} & \multirow{2}{*}{ Dyspnœa } & \multirow{2}{*}{$\begin{array}{l}\text { Systolic } \\
\text { murmur } \\
\text { only }\end{array}$} & \multirow[t]{2}{*}{ E.C.G. } & \multirow{2}{*}{$\begin{array}{c}\text { Systemic } \\
\text { blood } \\
\text { plessure } \\
(\mathrm{mm} . \mathrm{Hg})\end{array}$} & \multirow{2}{*}{$\begin{array}{c}\text { Arterial } \\
\mathrm{O}_{2} \\
\text { satura- } \\
\text { tion } \\
(\%)\end{array}$} & \multirow{2}{*}{ 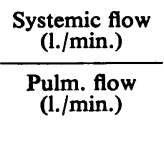 } & \multirow{2}{*}{$\begin{array}{c}\text { Volume } \\
\text { of left- } \\
\text { to-right } \\
\text { shunt } \\
\text { (1./min.) }\end{array}$} & \multicolumn{3}{|c|}{$\begin{array}{l}\text { Pulmonary arterial pressures } \\
(\mathrm{mm} . \mathrm{Hg})\end{array}$} & \multirow{2}{*}{$\begin{array}{l}\text { Residual } \\
\text { systolic } \\
\text { murmur }\end{array}$} \\
\hline & & & & & & & & & & $\begin{array}{c}\text { Pre- } \\
\text { operative }\end{array}$ & $\begin{array}{c}\text { Post- } \\
\text { operative }\end{array}$ & $\begin{array}{l}\text { At repeat } \\
\text { catheteri- } \\
\text { zation }\end{array}$ & \\
\hline 1 & $\mathbf{F}$ & $5 \frac{1}{2}$ & + & + & L.V.H. & $98 / 56$ & 92 & $\frac{t 3}{4 \cdot 4}$ & 1.4 & $90 / 55$ & $40 / 20$ & $26 / 10$ & + \\
\hline 2 & $\mathbf{F}$ & $5 \frac{1}{2}$ & + & - & L.V.H. & $93 / 50$ & 90 & $\frac{14}{4 \cdot 5}$ & 0.5 & $90 / 60$ & $40 / 20$ & $36 / 24$ & - \\
\hline 3 & $\mathbf{M}$ & $11 \frac{1}{2}$ & - & + & L.V.H. & $110 / 40$ & 93 & +3.5 & 3.5 & $90 / 40$ & $60 / 30$ & $55 / 25$ & + \\
\hline 4 & $\mathbf{F}$ & 9 & - & + & $\begin{array}{l}\text { Bivent. } \\
\text { Hyper. }\end{array}$ & $70 / 30$ & 89 & $\dagger \frac{3}{3 \cdot 3}$ & 0.3 & $100 / 50$ & $100 / 50$ & - & + \\
\hline 5 & $\mathbf{M}$ & $11 \frac{1}{2}$ & - & + & L.V.H. & $100 / 30$ & 93 & $\bar{F}$ & - & $110 / 50$ & $60 / 40$ & $45 / 5$ & - \\
\hline 6 & $\mathbf{F}$ & 13 & - & + & $\begin{array}{l}\text { Bivent. } \\
\text { Hyper. }\end{array}$ & $95 / 60$ & 94 & $\frac{T 2 \cdot 3}{3 \cdot 7}$ & 1.4 & $100 / 60$ & $100 / 60$ & $105 / 45$ & + \\
\hline 7 & $\mathbf{M}$ & 8 & - & + & L.V.H. & $100 / 65$ & 95 & $\frac{+3}{6}$ & 3 & $70 / 60$ & $30 / 20$ & - & - \\
\hline 8 & $\mathbf{F}$ & $4 \frac{1}{2}$ & - & + & L.V.H. & $95 / 60$ & 94 & $\frac{+2.5}{3 \cdot 2}$ & 0.7 & $85 / 40$ & $40 / 20$ & - & + \\
\hline 9 & $\mathbf{F}$ & 3 & - & - & L.V.H. & $90 / 60$ & 93 & $\frac{+3 \cdot 3}{5 \cdot 5}$ & $2 \cdot 2$ & $55 / 30$ & $30 / 20$ & - & - \\
\hline $\begin{array}{l}10 \\
11\end{array}$ & $\underset{F}{F}$ & $\begin{array}{l}4 \frac{1}{2} \\
6 / 12\end{array}$ & + & $\overline{-}$ & $\begin{array}{l}\text { L.V.H.H. } \\
\text { L.V.H. }\end{array}$ & $\begin{array}{l}90 / 60 \\
90 / 30\end{array}$ & $\begin{array}{l}93 \\
97\end{array}$ & $\bar{E}$ & 二 & $\begin{array}{l}90 / 50 \\
50 / 30\end{array}$ & $\begin{array}{l}50 / 30 \\
30 / 20\end{array}$ & $40 / 20$ & $\bar{z}$ \\
\hline 12 & $\mathbf{M}$ & $2^{2} / 12$ & - & - & L.V.H. & $110 / 40$ & 87 & $\frac{3.6}{3.6}$ & 0 & $70 / 40$ & $50 / 20$ & - & + \\
\hline 13 & $\mathbf{F}$ & $1^{4 / 12}$ & - & - & L.V.H. & $130 / 20$ & 90 & $\frac{* 1 \cdot 7}{2 \cdot 5}$ & 0.8 & $85 / 50$ & $40 / 5$ & - & - \\
\hline 14 & F & 4 & - & - & L.V.H. & $110 / 60$ & 92 & $\frac{2 \cdot 6}{4}$ & 1.4 & $55 / 40$ & $42 / 30$ & - & - \\
\hline 15 & $\mathbf{M}$ & $2^{4 / 12}$ & - & - & L.V.H. & $120 / 40$ & 94 & $\frac{\dagger 2.5}{5}$ & 2.5 & $60 / 30$ & $40 / 20$ & - & - \\
\hline
\end{tabular}

* Oxygen consumption estimated by Kipp Diaferometer.

† Oxygen consumption assumed from surface area according to formula of Nadas (1963).

shunt reversal had occurred. Moderate to severe cardiomegaly was seen in all 15 patients on cardiac screening, but in only 2 did this involve both ventricles.

\section{OPERATIVE DATA}

The technique employed in all was virtually identical. When the chest had been opened and the ductus dissected out, pressures were recorded in the pulmonary artery both before and after clamping of the ductus. In 13 the pressure fell significantly, but in the other 2 it remained unaltered. The ductus was then closed, by ligation in 11 and by division in 4 . Had any rise in pressure in the pulmonary artery been discernible after clamping, the ductus would then have been regarded as representing a safety valve and its closure would thus have been contraindicated.

Our custom following closure of an uncomplicated ductus arteriosus is to discharge the patient from hospital within 10 days. However, in those with pulmonary hypertension a strict regimen of bed-rest for two to three weeks was adopted, together with the prophylactic administration of digoxin during this period. These measures entailed a longer stay in hospital, but they seem justified by the absence both of mortality and major complications.

\section{FOLLOW-UP}

The 15 patients have been followed up for periods varying from two months to five years. All are active and symptomless. The second pulmonary sound has reverted to normal intensity in all but the two where the pulmonary hypertension has persisted. The cardiac enlargement has regressed clinically and radiologically (see Fig. 1 and 2). A short soft grade 1 systolic murmur 


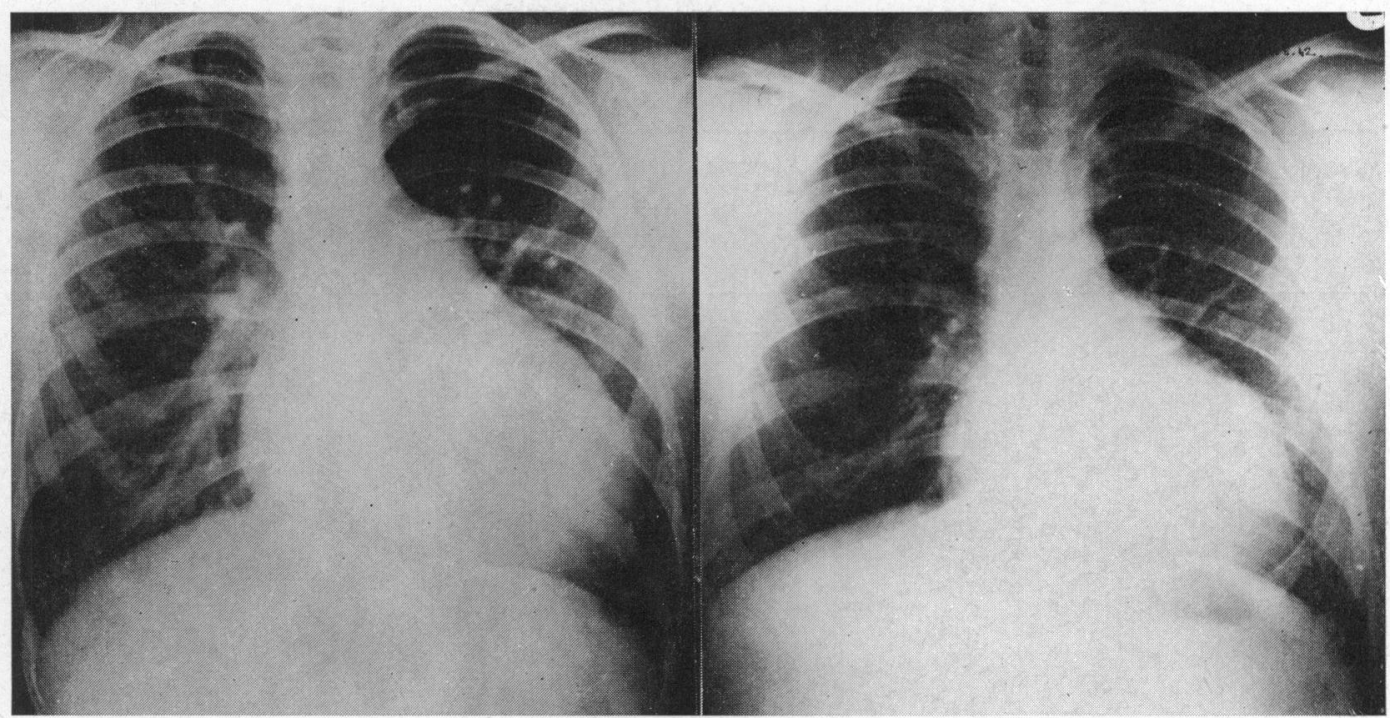

FIG. 1.-Pre- and post-operative chest radiographs of patient with patent ductus arteriosus and reversible pulmonary hypertension.

persists in 5, but this does not resemble either in intensity or duration that present before operation. The significance of this murmur is debatable, but the most likely explanation is that it represents persistent dilatation of the pulmonary artery at the site of the ligated ductus. Cardiac catheterization has been repeated in 6 patients, 3 of whom still have the systolic murmur referred to above. From neither blood oxygen values nor dye indicator curves is there any evidence of a residual shunt. Although Case 6 still has severe pulmonary hypertension two years after operation, she appears to be in robust health and there has been some reduction in cardiac size (Fig. 3). Case 4 was operated
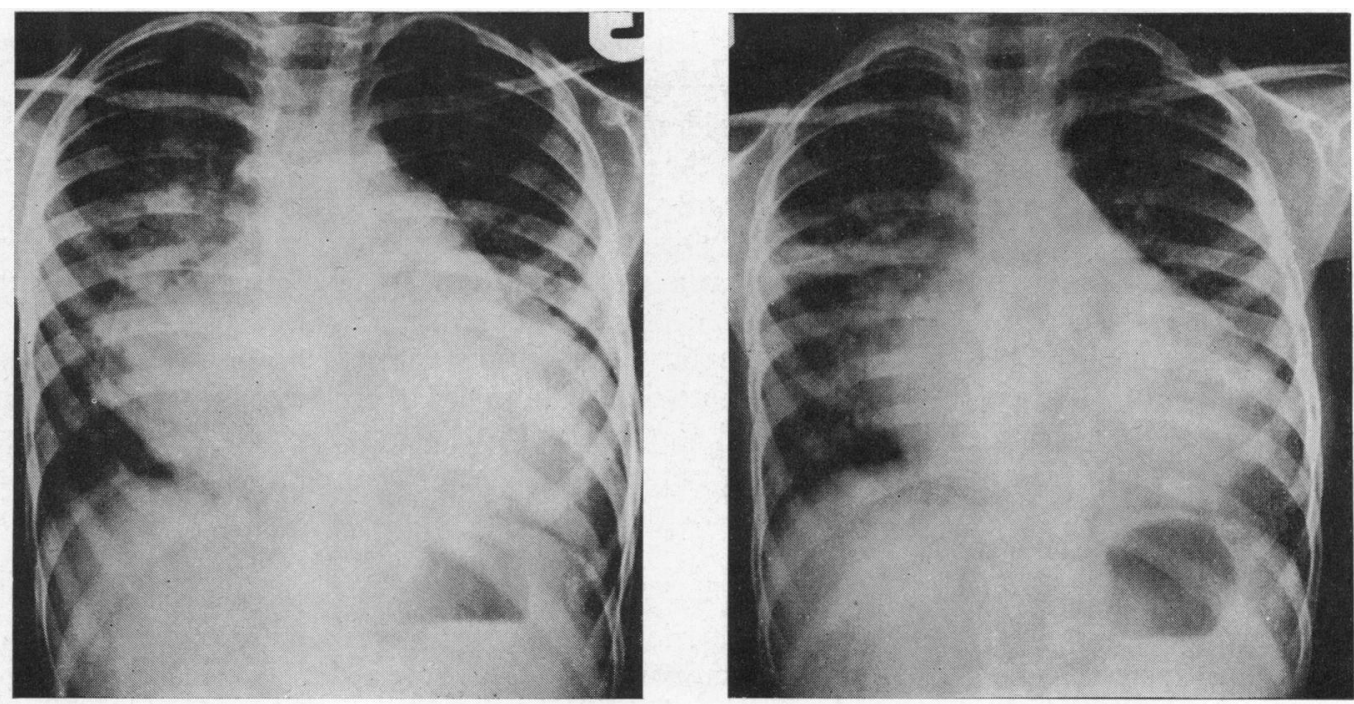

Fig. 2.-Pre- and post-operative chest radiographs of patient with patent ductus arteriosus, gross cardiomegaly, and reversible pulmonary hypertension. 


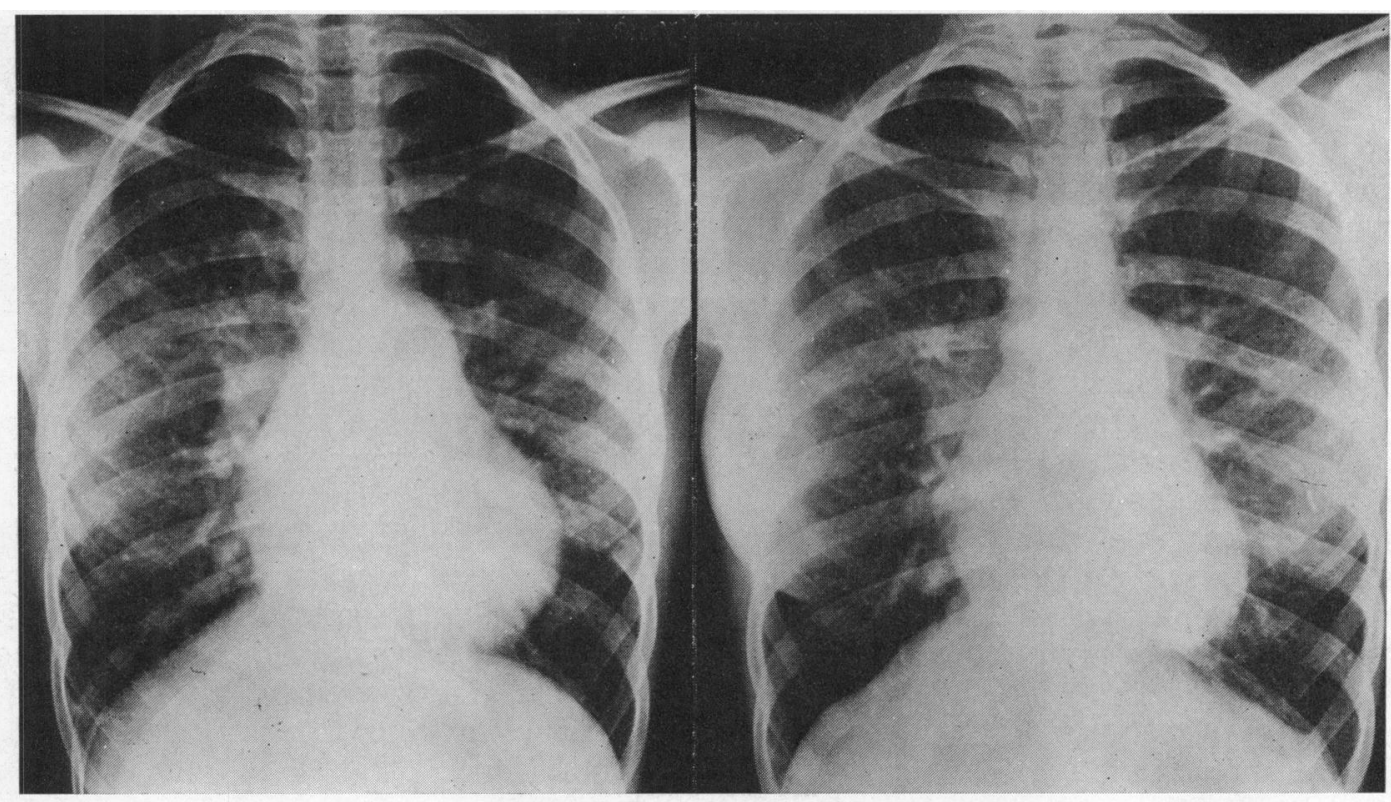

Fig. 3.-Pre- and post-operative chest radiographs of patient with patent ductus arteriosus and irreversible pulmonary hypertension.

on comparatively recently, and catheterization has not yet been repeated. The remainder have shown a substantial fall in pulmonary artery pressure.

\section{Discussion}

Dealing with the clinical aspect of patent ductus arteriosus with pulmonary hypertension, Evans and Short (1958) emphasized that cyanosis was a common finding, that the pulse was no longer collapsing, and that a continuous murmur was exceptional. Biventricular hypertrophy was indicated by the electrocardiogram. Fluoroscopy showed cardiomegaly, considerable dilatation of the main pulmonary arteries, and translucency of the lung periphery. Evans and Heath (1961) stressed that the presence of right ventricular hypertrophy shown by electrocardiography and radiography was indicative of pulmonary hypertension in patent ductus arteriosus. The existence of central cyanosis, however, implies shunt reversal and the establishment of the Eisenmenger syndrome (Wood, 1958b).

Taussig (1960) found that pulmonary hypertension was a comparatively infrequent phenomenon in patent ductus arteriosus as an isolated malformation, even when the ductus was large. In cases where it had occurred she distinguished two major categories: the first, which she referred to as primary, was not attributable to the ductus but to increased resistance within the pulmonary vascular bed persisting from fœtal life, and surgical closure of the ductus would, she maintained, produce no reduction in the pulmonary hypertension; the other type was secondary to a concomitant severe malformation of the left side of the heart, such as mitral stenosis, and in these circumstances surgical treatment, to be effective, must deal simultaneously with both malformations. Wood (1958a), discussing pulmonary hypertension in general, postulated six types: the second of these, namely hyperkinetic, he considered a response to increased pulmonary blood flow. It is remarkable, however, that pulmonary hypertension should so seldom complicate an isolated patent ductus arteriosus where a high pulmonary flow is the rule. If a ductus remains open indefinitely, permanent pulmonary hypertension, referred to by him as polygenic, may occur due to irreversible changes in the pulmonary arteries.

Nadas (1963) has classified pulmonary hypertension in association with a patent ductus arteriosus 
as either primary or secondary; the primary variety he attributed to persistence of the fœtal pulmonary vasculature, and the secondary variety to the effect of an excessive pulmonary blood flow. A distinction could not be drawn between these two varieties from the characteristics of the heart murmur or from the electrocardiographic or radiographic apearances. However, those with primary pulmonary hypertension were usually cyanosed and could be shown to have a high pulmonary vascular resistance. From this group an operative mortality of 50 per cent could be expected, because the pulmonary hypertension remained largely unaffected. In the secondary variety the pulmonary artery pressure reverted to normal after closure.

Anderson and Coles (1955), reporting on 9 children who were operated on for patent ductus arteriosus with pulmonary hypertension, put forward the view that pulmonary hypertension in this condition was basically due to increased pulmonary blood flow. Even where there was raised pulmonary vascular resistance and histological proof of structural changes in the lungs, the pulmonary hypertension might revert to normal following closure of the ductus.

Of the 15 cases comprising the present series 13 would fit the thesis that the pulmonary hypertension was due solely to the augmented pulmonary blood flow, since the pulmonary artery pressure showed a substantial fall either immediately or within a year after closure of the ductus. In the other two the pulmonary hypertension appears to have been primary since the pulmonary artery pressure failed to drop after closure. Although Kjellberg et al. (1959) asserted that several months or even a year might elapse before pulmonary hæmodynamics were restored to normal, the two under discussion appear unlikely to show any significant fall in the future.

Campbell (1955) concluded that closure of patent ductus arteriosus in the presence of hypertension might fail to affect this because extensive changes had already taken place in the pulmonary arterioles. Ellis et al. (1956) reviewed 30 cases of patent ductus arteriosus complicated by pulmonary hypertension (the pulmonary artery pressure exceeded $60 \mathrm{~mm}$. $\mathrm{Hg}$ in all). The over-all mortality rate was 18 per cent, but where shunt reversal had occurred the mortality rate reached the forbidding figure of 56 per cent. Cleland (1958) favoured closure of patent ductus arteriosus with pulmonary hypertension even where the systemic and pulmonary artery pressures were equal, and mentioned 14 patients treated with success. Harris and Heath (1962), in a comprehensive monograph on the human pulmonary circulation, related the reversibility or otherwise of pulmonary hypertension associated with congenital heart disease to structural changes in the media and intima of the small pulmonary arteries. They recognized six grades of severity; when grade 4, 5, or 6 was present, the changes had become so extensive that repair of the cardiac defect or closure of the ductus could not materially influence the pulmonary hypertension. They perform lung biopsy at the time of operation, and maintain that this is of inestimable value in assessing both the extent and severity of the pulmonary arterial changes, and hence is of help in prognosis. They described three principal phases in the development of hypertensive pulmonary vascular disease due to congenital cardiac anomalies. In the first of these, where pulmonary hypertension is due to increased pulmonary blood flow, closure of the defect restores circulatory hæmodynamics to normal. In the second phase, termed equal resistance, a high pulmonary vascular resistance has developed and the left-to-right shunt has declined in magnitude; correction of the defect, although perilous, is justified because without treatment the prognosis is grave. In the third phase pulmonary blood flow has diminished because the pulmonary vascular resistance now exceeds the systemic; this corresponds to the pathological grades 5 and 6 , and here there is no place for surgical treatment.

One might reasonably inquire whether closure of a ductus accompanied by severe and unremitting pulmonary hypertension is justifiable. There are at least two reasons; first to prevent any further rise in pulmonary hypertension through continuance of the increased pulmonary blood flow, and secondly to prevent subacute bacterial endocarditis (Gross, 1952; Krovetz and Warden, 1962).

Thus in our view the only contraindication to closure is the presence of shunt reversal, which may be indicated either by central cyanosis, by the results of catheter studies, or by a rise in pulmonary artery pressure following a test clamping of the ductus at thoracotomy (Ellis et al., 1956; Kjellberg et al., 1959; Wood, 1956). 


\section{SUMMARY}

In a series of 290 cases of patent ductus arteriosus treated by operation over a period of 12 years, 15 were encountered with a pulmonary artery pressure of $50 \mathrm{~mm} . \mathrm{Hg}$ or above. In all, closure was effected without mishap, although in 2 the pulmonary hypertension appears irreversible.

The authors wish to express their thanks for the help afforded by the Board of Management and the Benefactors of the Royal Hospital for Sick Children, Glasgow, and the Board of Management for the Victoria Group of Hospitals, Glasgow. They are also indebted to Professor J. H. Hutchison and Dr. R. A. Shanks and to the other physicians in the Region who referred their cases for treatment.

\section{REFERENCES}

Anderson, I. M., and Coles, H. M. T. (1955). Patent ductus arteriosus with pulmonary hypertension; a review of nine cases, including one with reversal of blood flow through the ductus. Thorax, 10, 338 .

Campbell, M. (1955). Patent ductus arteriosus; some notes on prognosis and on pulmonary hypertension. Brit. Heart J., 17, 511.

Cleland, W. P. (1958). Symposium on congenital heart disease (3): the level of pulmonary vascular resistance that contraindicates operation. Brit. Heart J., 20, 276.

Ellis, F. H., Kirklin, J. W., Callahan, J. A., and Wood, E. H. (1956). Patent ductus arteriosus with pulmonary hypertension. An analysis of cases treated surgically. J. thorac. Surg., 31, 268.

Evans, D. W., and Heath, D. (1961). Disappearance of the continuous murmur in a case of patent ductus arteriosus. Brit. Heart J., 23, 469.

—, and Short, D. S. (1958). Pulmonary hypertension in congenital heart disease. Brit. Heart J., $20,529$.

Gross, R. E. (1952). The patent ductus arteriosus. Observations on diagnosis and therapy in 525 surgically treated cases. Amer. J. Med., 12, 472.

- , and Hubbard, J. P. (1939). Surgical ligation of a patent ductus arteriosus. Report of first successful case. J. Amer. med. Ass., $112,729$.

Harris, P., and Heath, D. (1962). The Human Pulmonary Circulation, p. 157. Livingstone, Edinburgh and London.

Kjellberg, S. R., Mannheimer, E., Rudhe, A., and Jonsson, B. (1959). ' Diagnosis of Congenital Heart Disease, 2nd ed., p. 546. Year Book Publishers, Chicago.

Krovetz, L. J., and Warden, H. E. (1962). Patent ductus arteriosus. An analysis of 515 surgically proved cases. Dis. Chest, 42, 46.

Nadas, A. S. (1963). Pediatric Cardiology, 2nd ed. Saunders, Philadelphia and London.

Taussig, H. B. (1960). Congenital Malformations of the Heart, Vol. 2: Specific Malformations, 2nd ed., pp. 448 and 490. Published for the Commonwealth Fund by Harvard University Press, Cambridge, Massachusetts.

Wood, P. (1956). Diseases of the Heart and Circulation, 2nd ed., p. 380. Eyre and Spottiswoode, London.

(1958a). Pulmonary hypertension with special reference to the vasoconstrictive factor. Brit. Heart J., 20, 557.

(1958b). The Eisenmenger syndrome; or pulmonary hypertension with reversed central shunt. Brit. med. J., 2, 701 . 